\title{
THE EFFECTIVENESS OF A PROBLEM-SOLVING PROGRAM IN SOLVING THE MATHEMATICAL PROBLEM AMONG 10TH GRADERS IN LIGHT OF THEIR VARIANCE OF THE MATHEMATICAL SELF-CONCEPT
}

\author{
Ahmed Mohammed Al-Kharousi ${ }^{1}$, Adnan Salim Al-Abed ${ }^{2}$ \\ ${ }^{1}$ Ph.D. Candidate in Education, Ministry of Education, Oman, alkharosi_555@hotmail.com \\ ${ }^{2}$ Prof. Dr. at SQU, Oman \& JU, Jordan, a.abed@squ.edu.om
}

\begin{abstract}
This study aimed at investigating the impact of a problem-solving based program on mathematical problemsolving among 10th-grade students due to the variance of their mathematical self-concept. The purposive sample of this study consisted of (89) male and female students from Wadi Bani Kharous Basic Education School and Om Hakeem Basic Education School at Sultanate of Oman. The sample was divided into an experimental group, which consisted of (48) students, and the control group consisted of (41) students. The instructional materials of Polynomial and Algebraic Functions Unit and Trigonometric Functions Unit for Grade 10th were designed based on the problem-solving program. The problem-solving test and mathematical self-concept scale were developed, and both were valid and reliable. The findings showed that: there were significant statistical differences in the mathematical problem-solving test in favor of the experimental group. The findings indicated that the significant statistical differences in the mathematical problem-solving test are due to the mathematical self-concept and the absence of statistically significant differences in the mathematical problem-solving test is due to the interaction between teaching methods and mathematical self-concept in light of the findings, the study suggested some crucial recommendations including the importance of enriching mathematics curricula with mathematical problem-solving strategies and having professional development workshops to train teachers on how to use mathematical problemsolving strategies and urge them to use these strategies in teaching Mathematics.
\end{abstract}

Keywords: problem solving, mathematic, self-concept.

\section{INTRODUCTION}

The progress of countries is basically linked to the development of their sciences, especially mathematics. this is simply because mathematics is an important tool for realizing relationships, organizing ideas, and understanding the surrounding environment. It is a method of research that develops through the sensory experiences and its application in other sciences. In light of the development of science, there have been changes in mathematics which encompassed a development on all mathematics branches. These developmental changes have become an indispensable fundamental pillar in many social and natural humanities

With accordance to the outstanding importance of mathematics science and its pedagogy, it has been given special priority by the educational systems and the international bodies and organizations. For instance, the mathematics curriculum has received a great deal of interest included the development and innovation in its content, learning objectives and teaching methods. Thus, the purpose of mathematics teaching is not only developing the learners' cognitive aspect of knowing the laws, mathematical concepts, theories, postulates, assumptions, the calculations, but also developing the human mind, improving students' ways of sound thinking, and preparing the individuals who are able to employ mathematical knowledge in solving various 
problems and in dealing with attitudes and life problems imposed by the requirements of society and the new developments of the modern era (Gad, 2009; Qassi, 2014).

Expanding the goals of mathematics to include different fields of growth requires reconsideration of the mathematics display content with indirect teaching strategies based on learner's extrapolation and problemsolving. This requires the teacher to select teaching strategies to enrich the learners and develop their different mental skills and to give them the right ways of thinking so that they can solve what they face in real-life situations. In addition, these selective teaching strategies should train them to innovate, produce new knowledge, and develop trends towards mathematics. Therefore, the mathematics teacher has to be aware of certain aspects including various teaching strategies and their role in education, the importance of listening and paying attention to students' ideas, using new methods to solve problems, and providing information and lessons on problems modality. Being aware of all these aspects has the impact of inspiring the creative energies of students by showing their opinions and ideas to solve the problem, listen to the opinions of others, to constructively criticize them in order to reach solutions for these problems that contribute to preparing students to face the problems in real-life situations (James, 2005).

On the other hand, the objectives of mathematics education now emphasize the need to focus on the problem-solving as a major goal in the teaching of mathematics. National Council of Teachers of Mathematics) NCTM, 2000); the highest and largest body dealing with mathematics education, considers solving the mathematical problem as one of the main criteria in mathematics education. It recommends the necessity to focus on the problem-solving and requires the presentation of mathematics topics through problem-solving that enable the students to develop solutions and skills, to gain concepts and generalizations, or to enhance previous knowledge. This is an incentive to learn mathematics and makes it a meaningful material related to the real-life situations and needs of learners.

Solving mathematical problems has a long history in mathematics school, which has been used to achieve a variety of goals that have changed over time. The most well-known advocate of problem-solving in the early 20th century was George Pulya (1945) who stressed in his book (How to Solve It) the use of inference in order to develop the ability of students to solve problems (Banes, 2013).

Many studies have shown that students' weakness in using their mathematical knowledge in everyday life may be due to various reasons. One of the important reasons is the display and presentation of mathematical problems. The second reason is the common content in most of the problem-solving activities that focus only on the classroom environment and often have only one solution. The third reason is writing specific steps for the solution of the problem even if the problem does not enquire these steps (Bonotto, 2011; Al-Badri, 2017). Additionally, studies have emphasized the need to design the Math curriculum based on mathematical problem-solving in order to develop the level of mathematical thinking for the students and their ability to use mathematical knowledge to infer and formulate appropriate mathematical rules (Sangpom, Suthisung, Kongthip \& Inprasitha, 2016).

The interest in solving problems in contemporary educational trends is evident in a tangible way. Various studies have pointed out the importance of using problem-solving and its effectiveness as a strategy to develop the curricula of mathematics. For instance, Al Badri (2017) investigated the effectiveness of an enrichment program based on solving mathematical problems and their role in the development of the ability to infer and form a sense of mathematics among high-achieving students in the 10th grade. A test has been designed in inference and mathematical sense. The study sample consisted of (63) students of highachieving students in the 10th grade and was divided into two groups, experimental and control. The study found that the experimental group acquired inference skills and the ability to form a mathematical sense. Added to that, the findings indicated the effectiveness of the proposed program in the development of inference and the formation of mathematical sense among the students.

\subsection{Literature Review}

Al-Zoubi's study (2014a) aimed to investigate the impact of a problem-solving strategy in the development of Mathematics creative thinking skills among students of a class teacher at Yarmouk University. The sample consisted of (98) students divided into two groups: an experimental group with (48) students and a control group with (50) students. The study instrument was a test of creative thinking. The results of the study showed an improvement in mathematical creative thinking skills (fluency, flexibility, and originality) among students in the experimental group. The study also found statistically significant differences between the experimental and control groups in fluency, flexibility, originality, and overall test scores in favor of the experimental group. The study recommended the use of a problem-solving program because of its role in developing creative thinking skills.

Al-Zoubi's study (2014b) investigated the effectiveness of using a problem-solving teaching strategy in the 
development of numerical sense among students in the class teacher at Muta University. The study sample consisted of (87) student teachers, divided into two groups, experimental group with (45) students teachers studied using the teaching strategy and control group with (42) student teachers studied in the usual teaching method. A numerical sense test was built that included numerical perception skills, process perception and numerical relationships, computational, and mental appreciation and responding logic. The results of the study showed that the students of the experimental group outperformed the control group in the test of the numerical sense and in all numerical sense skills except the skill of the perception of number.

Shubair (2011) conducted a study that aimed to find out the impact of the problem-solving strategy in treating Mathematics learning difficulties in eighth-graders. The study adopted the analytical descriptive and quasiexperimental designs. The study sample consisted of (613) students divided into the experimental group who studied the problem-solving strategy and the control group who studied the usual teaching method. The study instrument consisted of a test (diagnostic/ achievement) on the unit of trigonometry in the eighth-grade mathematics book. The results of the study found that there are statistically significant differences at the level of significance $(\alpha<.0 .01)$ in the mean scores of the post-test between the two groups in favor of the experimental group. The study recommended that a problem-solving strategy should be used to teach mathematics to eighth grade.

Al-Khatib and Ababna's Study (2011) aimed to investigate the impact of a problem-solving strategy on mathematics thinking and attitudes towards mathematics in seventh grade in Jordan. The study sample consisted of (104) students divided into two random groups; an experimental group studied using a problemsolving strategy and a control studied in the usual way. The results on mathematical thinking showed that the students of the experimental group outperformed those of the control group. It also found that there were no statistically significant differences in mathematical thinking due to the interaction between the teaching strategy and the achievement level. The attitudes of the students in the experimental group were better than those of their peers in the control group. Additionally, there were no statistically significant differences in students' attitudes towards mathematics attributed to the interaction between the teaching strategy and the achievement level.

According to the significance of using strategies to solve mathematical problems, this study aimed to examine the effectiveness of a problem-solving program among students in the tenth grade based on the variance of their mathematical self-self.

\section{PROBLEM STATEMENT}

Mathematics problem-solving is on the top 10 basic skills of Math curriculum included in the document by the National Council of Teachers of Mathematics in United States of America (NCTM). Thus, the development of students' ability to solve Math problem has been a major concern among Mathematics educators (Abu Zeina, 2010).

The results of the international study (TIMSS) for the academic years 2007, 2011, and 2015 showed a decline and low achievement of students in Mathematics in Oman. The results of the Sultanate of Oman is still far from the global average (IEA, 2017; National Report of the International Study in Math and Science, 2013). This decline may be due to students' weakness and inability to solve Mathematics problems as students of all levels of achievement spend most of their time and effort sorting and extracting data and linking them with each other to identify the problem and create a solution plan, which in turn confirms that a deep understanding of the mathematics problem is the main focal point to solve it.

As for the mathematical self-concept, the relationship of mathematical self-concept to achievement in Mathematics is interactive and mutual. The mathematical mental processes contribute to the development of mathematical self-concept. Additionally, achievement in Mathematics increases by the improvement of the mathematical self-concept of the students (Al Abed \& Majdlawi, 2016).

In light of that, there is a need to provide a problem-solving educational program that can contribute to the development of mathematical problem-solving based on the mathematical self-concept. Therefore, this study aimed to answer the following main question: What is the effectiveness of a problem-solving program in solving the mathematical problem among 10th grade in light of the variance of their mathematical selfconcept?

\section{RESEARCH QUESTIONS}

The following sub-questions emerged from this question:

Question 1: What is the effectiveness of a problem-solving educational program in solving the mathematical problem among 10th graders? 
Question 2: Does the solution to the mathematical problem of 10th Does grade differ according to their mathematical self-concept (high, low)?

Question 3: Is there any effect on the mathematics problem- solving due to the interaction between the teaching method (the proposed program and the usual method) and the mathematical self-concept (high and low) among 10th grade students?

\section{STUDY HYPOTHESES}

According to the main research question and based on the sub-questions, the null hypotheses were formulated as follows:

Hypothesis 1: there is no statistically significant difference at the level of significance $(\alpha=0.05)$ between the average grades of students of the experimental group who studied according to the problem-solving program and the average score of the students of the control group (studied in the usual way) in the test to solve the mathematical problem.

Hypothesis 2: There is no statistically significant difference at the level of significance $(\alpha=0.05)$ in the test to solve the mathematical problem of 10th grade due to their mathematical self-concept (high, low).

Hypothesis 3: There is no statistically significant difference at the level of significance $(\alpha=0.05)$ in the mathematical solution test due to the interaction between the group (experimental, control) and the mathematical self-concept (high, low) in tenth-grade students.

\subsection{Study Objectives}

The study aimed to examine the effectiveness of a problem-solving program to solve mathematics problem among 10th grade in light of their diverse mathematical self-concept.

\section{RESEARCH METHODOLOGY}

This study adopted the quasi-experimental design based on two groups; experimental group and control group. The experimental group studied the two units of Polynomial and Algebraic functions (Unit 5) and Trigonometric functions (Unit 6) using a mathematical problem-solving program prepared by the researcher. The control group studied the same two units in the usual way. After the treatment, the two groups took a test to solve the mathematical problem, and the students in the two groups were classified in the light of their mathematical self-concept.

\subsection{Sample of the Study}

A purposive sample of this study consisted of (89) male and female students from Wadi Bani Kharous Basic Education School and Om Hakeem Basic Education School at Sultanate of Oman. The sample was divided into an experimental group, consisted of (48) students, and the control group wich consisted of (41) students. The experimental group studied by using an educational program of mathematics problem-solving while the control group studied in the usual teaching method.

\section{PRPBLEM-SOLVING PROGRAM}

\section{First: The objectives of the educational program}

The overall objectives of the educational program can be determined as follows:

1. Develop students' ability to solve and interpret Math problems.

2. Develop students' ability to accurately organize and arrange the information.

3. Develop students' ability to generate the greatest number of solutions to the mathematical problem in a specified period of time.

4. To enhance the student's self-confidence and self-realization by encouraging them to have dialogues and discussions and listen to others' opinions.

\section{Second: Content of the educational program}

After reviewing theoretical literature and previous studies on the solution of Mathematical problems, and after setting the general objectives of the program, the content of the program, which consists of the fifth and sixth units (Polynomial and Algebraic Functions Unit and Trigonometric Functions Unit) were selected from the Math curriculum of semester 2 for grade 10. The content is organized in a way that suits students' preferences and takes into account the integration of educational experiences and a variety of activities. 


\section{Third: Identifying the teaching strategies and methods of the educational program}

Several strategies were used to implement this program including:

- Modeling.

- Start with a simpler problem.

- Revers solution.

- Open mathematical sentence strategy (organizing equations or inequalities).

- Logical justification strategy.

Fourth: Identify activities and instructional materials associated with the educational program

The educational activities and instructional materials associated with the program are an important element in designing the educational program. This is because they are directly linked to achieving the objectives of the program. Various activities were prepared to increase the effectiveness of the proposed educational program and instructional materials including laws and geometric shapes, models of shapes and figures, and classroom worksheets. In addition, activities book containing a summary of lessons and exercises supporting the educational program was prepared. The educational program emphasized strategies such as group discussions and reinforcement of individual participation. The researcher followed some criteria in order to identify the educational activities and materials associated with the program such as:

1. Educational activities and materials should be suitable for the content and objectives of the program.

2. Educational activities and materials should consider differences in the level of the students and should motivate students to accomplish the required tasks.

3. Educational activities and materials should enhance students' ability to solve Math problem.

4. Educational activities and materials should stimulate students' thinking.

5. Educational activities and materials should be achievable in light of the possibilities available.

\section{Fifth: The technology used in the program}

Technology has become widely spread in the educational context. A variety of technological tools were used by educators, projectors, interactive whiteboard, and some computerized software such as GeoGebra, Graphmatica to name but a few.

\section{Sixth: Determining the time and spatial limit of the educational program}

The program targeted students in the 10th grade of the second semester of the 2018/19 academic year. The program was implemented in the eight-week period at the rate of seven classes per week, and the duration of each class (45 minutes).

\section{Seventh: Identify the evaluation methods used in the educational program}

The evaluation process aims to determine the extent to which the objectives of the program as a whole have been achieved, and the following evaluation methods have been used in the program:

Pre-assessment: The goal is to determine the extent to which students are able to develop the skills that the program seeks to develop. The pre-assessment included mathematical solution test and mathematical selfconcept measure which was both conducted before the treatment.

Formative assessment: This assessment was done during the implementation of the program through a range of activities associated with the skills to be developed and the feedback of any student who has a weakness in any skill.

Post- assessment: this was implemented at the end of the program through the re-implementation of the mathematical solution test in order to measure the difference between the pre-assessment and the postassessment and to monitor the impact of the implementation of the program on solving the mathematical problem.

\subsection{Research Instruments}

To achieve the objectives of the study, two instruments were developed: a Mathematics problem- 
solving test and a mathematical self-concept scale. The aim of the Mathematics problem-solving test is to measure the ability of the 10th graders to solve the mathematical problem associated with the mathematics subject in the 10th-grade course in the two units mentioned earlier. The test was initially constructed and included 15 questions, 10 of which were in the form of multiplechoice and 5 in the form of essay questions. In order to ensure the validity of the test, it was presented to specialists in the fields of Math curricula, teaching methods, measurement and evaluation. The group of evaluators included members of academic bodies at universities, educational supervisors and teachers to express their opinions and suggestions on the test were introduced. Some minor adjustments were made including on the language formulation of some vocabulary and one of the multiple choice questions was deleted. The test ended in its final form with (9) multiple-choice and (5) essay questions. The test was applied to a survey sample to verify the appropriate time for the test, to calculate the coefficients of difficulty and discrimination, and to extract the stability coefficient. The appropriate time for the test was found to be 50 minutes. Difficulty coefficients ranged from (0.37-0.70) which means that the test items are suitable for use in the study. , the researcher piloted the test to measure its reliability which was found (87.0) which is an acceptable value for the study purposes.

In regard to a mathematical self-concept scale, the purpose of classifying the study members according to their mathematical self-concept to a high and low level, the educational literature related to the mathematical self-concept has been reviewed. The scale sought by the study of Magdalene and Abed (2016) as the appropriate items were extracted and reformulated based on the age group (10th grade) and the clarity of its language formulation and simplicity. The mathematical self-concept scale consisted of (20) items, including (8) positive items $(3,4,6,9,10,16,19,20)$ and (12) negative items $(1,2,5,7,8,11,12,13,14,15,17,18)$ and graded response on the (Likert Scale) As follows: (Strongly agree $=5$, Agree $=4$, Neutral $=3$, Disagree $=2$, Strongly Disagree $=1$ ), negative items were treated in reverse in the calculation of grades. To ensure the validity of the scale, it was presented to specialists and they all made observations related to the reformulation of some phrases and the balance between negative and positive phrases. The reliability of the scale was verified by the test-retest method (stability over time). The test was re-piloted with a sample of (34) students two weeks after the first application and the Pearson correlation coefficient was calculated between the two applications and it was (0.844).

\section{FINDINGS AND DISCUSSION}

\subsection{Statistical Processing}

The quantitative data collected via the test scores and mathematical self-concept scale were statistically analyzed using SPSS (Statistical Package for the Social Sciences) software. For statistical analysis, the researcher employed SPSS for data processing including descriptive statistics of means and standard deviations. the researcher also used the 2×2-designed (two-way ANCOVA) analysis to adjust the differences between the mean scores of two groups in the pretest and post-test. Eta Square (n2) was also calculated to measure the size effect of the proposed mathematics problem-solving program.

\subsection{Findings and Discussion}

To answer the study questions and test the associated hypotheses, the mean scores and the standard deviations of test scores in the experimental and control groups were calculated as shown in Table (1).

Table 1: Mean scores, standard deviations and averages adjusted of the pre and post-test scores.

\begin{tabular}{|c|c|c|c|c|c|c|c|}
\hline \multirow{2}{*}{ Group } & Mathematical self- & \multirow{2}{*}{$\begin{array}{c}\text { Number } \\
\text { concept level }\end{array}$} & \multicolumn{2}{|c|}{ Pre-test } & \multicolumn{3}{|c|}{ Post-test } \\
\cline { 3 - 8 } & & & Mean & $\begin{array}{c}\text { Standard } \\
\text { deviation }\end{array}$ & Mean & $\begin{array}{c}\text { Standard } \\
\text { deviation }\end{array}$ \\
\hline & high & 25 & 6.92 & 2.68 & 20.32 & 4.56 & 19.52 \\
\hline Experimental & low & 23 & 5.48 & 2.71 & 13.91 & 5.00 & 13.96 \\
\hline & total & 48 & 6.23 & 2.78 & 17.25 & 5.73 & 16.74 \\
\hline & High & 21 & 5.52 & 2.38 & 15.19 & 6.70 & 15.21 \\
\hline
\end{tabular}


IJASOS- International E-Journal of Advances in Social Sciences, Vol. VII, Issue 19, April 2021

\begin{tabular}{|c|c|c|c|c|c|c|c|}
\hline \multirow{2}{*}{ Control } & Low & 20 & 3.95 & 2.23 & 8.25 & 4.70 & 9.18 \\
\cline { 2 - 8 } & total & 41 & 4.79 & 2.42 & 11.80 & 6.73 & 12.20 \\
\hline \multirow{2}{*}{ Total } & High & 46 & 6.28 & 2.61 & 17.98 & 6.14 & 17.36 \\
\cline { 2 - 8 } & Low & 43 & 4.77 & 2.59 & 11.28 & 5.59 & 11.57 \\
\cline { 2 - 8 } & total & 89 & 5.55 & 2.69 & 14.74 & 6.75 & 14.47 \\
\hline
\end{tabular}

Table (1) shows that there are significant differences between the mean scores of students of the experimental and the control groups. The results indicate that the mean score of the experimental group test scores was (6.23) and the standard deviation (2.76), while the mean score of the control group was (4.76) and standard deviation (2.42). This shows that there was a difference in the mean score indicated by (1.47) between the two groups before the treatment.

The results also indicate that there are significant differences between the mean scores of the experimental group and the control group in the post-test scores. with a mean score of (17.25) and standard deviation of (5.73) for the experimental group and mean score of (11.80) and standard deviation of (6.73) for the control group. This indicates that there is a difference in the mean scores of the two groups $(M=5.45)$.

Table (1) also shows that there are significant differences between the mean scores of high-level mathematical self-concept students and low-self-concept students in the pre-test (1.51). The mean score of students with high mathematical self-concept is (28.6) and the standard is (2.61) whereas the mean score of students with low mathematical self-concept is (4.77) with a standard deviation of (2.59). It is also noted that there is a difference between the mean scores of the students with high mathematical self-concept and students with low mathematical self-concept in the post-test $(M=70.6)$ as the mean score of the student with high mathematical self-concept was (17.98) With standard deviation (6.14) and the mean score of the students with low mathematical self-concept was (11.28) with a standard deviation of (5.59).

To find out whether there is any statistical differences $(\alpha=0.05)$ in the mean scores of the students of the experimental and control groups in the post-test and in order to isolate the differences between the two groups in the pre-test, Two-Way ANCOVA analysis with the $2 \times 2$ design was used. The ETA (n2) was also measured to identify the size effect of using the educational program test and the results were as in table 2.

Table 2: The results of the analysis of the accompanying two way analysis of variance

\begin{tabular}{|c|c|c|c|c|c|c|}
\hline $\begin{array}{c}\text { Source of } \\
\text { variance }\end{array}$ & $\begin{array}{c}\text { Sum of } \\
\text { squares }\end{array}$ & $\begin{array}{c}\text { Degree of } \\
\text { freedom }\end{array}$ & $\begin{array}{c}\text { Mean } \\
\text { squares }\end{array}$ & "F" value & $\begin{array}{c}\text { Significance } \\
\text { level }\end{array}$ & $\begin{array}{c}\text { ETA } \\
\text { square }\end{array}$ \\
\hline pre test & 184.025 & 1 & 184.025 & 7.077 & 0.009 & 0.078 \\
\hline $\begin{array}{c}\text { Teaching } \\
\text { method }\end{array}$ & 419.509 & 1 & 419.509 & 16.133 & 0.000 & 0.161 \\
\hline $\begin{array}{c}\text { Self- } \\
\text { concept }\end{array}$ & 678.819 & 1 & 678.819 & 26.106 & 0.000 & 0.237 \\
\hline interaction & 1.151 & 1 & 1.151 & 0.044 & 0.834 & 0.001 \\
\hline Error & 2184.229 & 84 & & & & \\
\hline total & $\mathbf{2 3 3 5 0}$ & $\mathbf{8 9}$ & & & & \\
\hline
\end{tabular}

The results in table (2) indicate statistically significant differences between the mean scores of the two groups on the post-test. The value of $(F)$ was (16.13) and this value is statistically significant at $(\alpha=0.05)$ between the mean score of the students who were taught using the educational program based on the solution of mathematical problems, and the average score of those who were taught in the usual way. This leads to the rejection of the first hypothesis: 'There is no statistically significant difference at the level of significance $(\alpha=0.05)$ between the mean scores of 
the experimental group students who studied according to the problem-solving program and the mean score with students of the control group who studied in the usual way. Thus, the educational program improved the ability of the students of the experimental group to solve the mathematical problem, compared to the students of the control group.

The ETA square (n2) was calculated and found to be (0.16). It can be said that approximately $16 \%$ of the variation in the mathematical problem -solving between the experimental and control groups is due to the educational program.

There was a difference between the mean scores of the post-test for the control and experimental groups in the post test in favor of the experimental group with an adjusted mean score of (16.74) compared to the adjusted mean score of the control group which was (12.20)

This positive result can be attributed to the impact of using the problem-solving program in math problemsolving to the following factors:

- The way lessons are carried out in accordance with problem-solving learning has helped students to acquire skills and knowledge through the systematic presentation of the lesson content in a variety of ways.

- Presenting various problems that simulate real-life situations during the problem-solving program may have a positive role in providing students with the skills to solve the mathematical problem by applying them in multiple and similar situations.

- The positive effect of students' learning with real problems in overcoming the dislike of math learning, due to the abstract nature that overcomes the subject, consequently; increases their interest in learning, increases their ability to solve math problems.

- The problem-solving program provides a variety of opportunities and multiple sources of knowledge for students by focusing on discussion, dialogue and working in groups, and urging them to exchange ideas, support them with justifications and verify their validity, which has played a role in creating an appropriate and encouraging learning environment.

- The Organized steps of problem-solving, that linked students' past experience to new experience in order to create meaningful learning, may play a role in helping them resolve math problems better and more accurately.

Referring to the analysis of the common variation in table 2 , the results indicate a statistically significant difference at the level of indication $(\alpha=0.05)$ between the mean scores of students with high mathematical self-concept and the students with low mathematical self-concept in the post-test. The value of $(F)$ was (26.106) which indicates that there is a statistical difference that may be attributed to the difference of the mathematical self-concept. Thus, the second null hypothesis, which arises from the second question, states: 'There is no statistically significant difference at the level of indication $(\alpha=0.05)$ in the test of solving the mathematical problem of tenth grad due to their the mathematical self-concept (high, low)', which means that the self- concept determination is due to the concept of their mathematical self (high, low)', which means that the mathematics self-concept has a positive impact on solving the mathematical problem.

To identify the effect size of the mathematical self-concept variable in resolving the mathematical problem according to the post-test, the ETA (n2) was calculated at (0.24). So it can be said that approximately $24 \%$ of the variation in the solution to the mathematical problem among students is due to their mathematical selfconcept variable.

The existence of statistically significant differences in the test of $10^{\text {th }}$-grade students can be attributed to their mathematical self-concept (high, low) due to the following factors:

- The high positive expectations of the students with high mathematical self-concept and their positive beliefs, which is reflected in their ability to solve the problem, as opposed to the students with low mathematical self-concept.

- The initiative, enthusiasm, desire and confidence of those who have high math self-concept have positively reflected in their ability to solve math problems.

Referring to the results in table (2), it is found that there are no statistically significant differences between the mean scores of students in the two groups due to the interaction between the teaching method and the mathematical self-concept of the students. The value of $(F)$ was $(0.44)$, thus there are no statistically significant differences at the level of $(\alpha=0.05)$ in resolving the mathematical problem among students who taught by the educational program and those who were taught by the usual teaching method. Thus, the third null hypothesis, which arises from the third question, which states: 'There is no statistically significant 
difference at the level of indication $(\alpha=0.05)$ in the mathematical solution test due to the interaction between the group (experimental, control) and their mathematical self-concept (high, Low) for 10th graders.

\section{RECOMMENDATIONS}

In the light of the results of this study, the following recommendations can be made:

- Preparing the curriculum for teaching Math in accordance with problem-solving learning because it has a positive impact on motivating students towards learning.

- Enrich mathematics books with mathematical problem-solving strategies.

- Training courses and workshops to train teachers to use problem-solving strategies to increase their ability and increase their professional competence in teaching Math.

- Conducting studies to research the program based on solving mathematical problems on other educational variables such as achievement, motivation, attitude, and logical thinking.

- Conduct studies to research the use of problem-solving software in other stages and classes.

\section{REFERENCE LIST}

Abu Zeina, Farid Kamel (2010). Develop and learn school math curricula. Oman: Wael Publishing House.

Al-Badri, Salama Bint Saeed Bin Mohammed (2017). The effectiveness of a program based on the formation and resolution of mathematical problems in the development of the ability to infer, form a mathematical sense and solve math problems and their composition among high-achieving students in the tenth grade according of their mathematical strength (unpublished PhD thesis). Sultan Qaboos University, Faculty of Education, Oman.

Al-Badri, Samira Musa (2005). Educational and psychological terms. Amman: Culture House for Publishing and Distribution.

Jad, Nabil Salah Al-Masilahi (2009). The effectiveness of a proposed unit according of the structural model in the development of math strength in middle school students, Journal of math Education, 12, 69-130.

Al-Khatib, Mohammed; and his son, Abdullah (2011). The impact of using a problem-solving teaching strategy on math thinking and attitudes towards math in Jordan's seventh grade. Journal of Educational Sciences, 38(1), 189-205.

Al-Zoubi, Ali Mohammed Ali (2014a). The impact of a problem-solving teaching strategy in the development of math creative thinking skills among students of a class teacher. Jordanian Journal of Educational Sciences, 10(3), 305-320.

Al-Zoubi, Ali Mohammed Ali (2014 b). The effectiveness of a teaching strategy based on solving mathematical problems in the development of the numerical student sense of education/ classroom teacher Jordan. Mutah for Research and Studies: Humanities and Social Sciences, 29 (2), 167-204.

Mr. Walaa Abdul Fattah Ahmed (2017). The effectiveness of the project-based learning strategy in teaching the assessment and diagnosis course in special education on the academic self-concept and academic achievement among the students of the Special Education Department Prince Sattam Bin Abdulaziz University. Arab Studies in Education and Psychology - Saudi Arabia, 88, 23-44.

Shabir, Imad Ramadan Mohammed (2011). The impact of the problem-solving strategy on treating math learning difficulties in eighth grade (unpublished master's thesis). Al-Azhar University, Gaza.

Shoihi, Hasser Bin Hassan Bin Mohammed (2016). A proposed enrichment program based on the model of creative problem solving in the teaching of math and its impact on the development of the thinking skills of divergence and mental motivation in talented students in the first grade of secondary school (unpublished PhD thesis). King Khalid University, Faculty of Education, Saudi Arabia.

Al-Abed, Adnan; AL-Shara, Ibrahim (2014). The learning aspects of math in students and their influence on the of their mathematical self-concept and their relationship to their achievement in math. Al-Najah University Research Journal (Humanities), 26(9), 2065-2104.

Abdelkader, Khaled (2013). Difficulties in resolving the verbal problems in math in the sixth grade in Gaza 
governorate point of view. Al-Aqsa University Journal, 17(3), 77-106.

Qasi, Salima(2014). The extent to which students in the fifth grade of primary school acquire the mathematical thinking skills contained in the new math curriculum. Journal of Humanities and Social Sciences, 14, 170-182.

Almajllawoi, Hamza mohammed and Al-Abed, Adnan (2016). The impact of the use of selective models on the achievement of sixth grades in math and their mathematical self-concept. Al-Manara Journal of Research and Studies, 22(3), 378-416.

Ministry of Education (2013). National Report of the International Study in Mathematics and Sciences for eighth grade, TIMSS (2011). Muscat: Ministry of Education.

Banes, B. C., (2013). A study of preservice elementary teachers learning mathematics through problembased learning and problem solving (Unpublished doctorate dissertation). Middle Tennessee State University

Bonotto, C. (2011). Engaging students in mathematical modelling and problem posing activities. Journal of Mathematical Modelling and Application, 1(3), 18-32.

Bruun, F. (2013). Elementary Teachers Perspectives of Mathematics Problem Solving Strategies. Mathematics Educator, 1(23), 45-59, EJ1020068.

Chapman, O. (2010). Constructing Pedagogical Knowledge of Problem Solving: Preservice Mathematics Teachers. Proceedings of the 29th Conference of the International Group for the Psychology of Mathematics Education, Ontario, February, 2010.

Dickha, O. (2005). Teachers' inferences about students' self-concept in the role of dimensional comparison. Learning and Instruction, 15, 225-235.

Dixon, R. \& Brown, R. (2012). Transfer of Learning: Connecting Concepts during Problem Solving. Journal of Technology, 1(23), 2-17, EJ991236.

International Association for Evaluation of Educational Achievement (IEA), (2017), TIMMS 2015 and TIMSS advanced 2015 international results. http://www.iea.nl/timss

James, E. (2005). Constructing a Math Applications, Curriculum-Based Assessment: an Analysis of the Relationship between Application problems, Computation Problems and Criterion-Referenced Assessments. DAI-B, 66(7): 3933.

McMoach, B. \& Siegle, D.(2003).The structure and function of academic self-concept in gifted and general education students. Roeper Review, 25(2), 61-65.

National Council of Teacher of Mathematics (NCTM). (2000). Principles and Standards for School Mathematics. Reston, VA: National Council of Teacher of Mathematics.

Sangpom, W., Suthisung, N., Kongthip, Y., \& Inprasitha, M. (2016). Advanced mathematical thinking and students' mathematical learning: Reflection from students' problem-solving in mathematics classroom. Journal of Education and learning, 5(3), 72-82.

Siobhan, H. (2007): Improving Basic Math Skills Using Technology (ED512698).

Trna, J. (2014). IBSE and Gifted Students. Science Education International, 25(1), 19-28. 